\title{
HYPERGLYCEMIA: A BAD PROGNOSTIC FACTOR FOR NEONATE.
}

1. MBBS, DCH, FCPS (Paediatrics), FCPS (Neonatology)

Assistant Professor Neonatology

Quaid e Azam Medical College/

Civil Hospital Bahawalpur, Punjab,

Pakistan

2. FCPS (Paediatrics), FCPS

(Neonatology)

Senior Registrar Neonatology Civil Hospital Bahawalpur, Punjab,

Pakistan

3. FCPS (Paediatrics)

Senior Registrar Pediatrics,

Civil Hospital Bahawalpur, Punjab, Pakistan.

Correspondence Address:

Dr. Muhammad Anwar

Department of Neonatology

Quaid-e-Azam Medical College/

Civil Hospital Bahawalpur, Pakistan.

hmanwar157@yahoo.com

Article received on:

20/01/2020

Accepted for publication:

$13 / 04 / 2020$

\section{INTRODUCTION}

Hyperglycemia is a commonly noticed metabolic abnormality among sick neonates. ${ }^{1}$ General criteria for diagnosis of neonatal hyperglycemia is considered to be glucose levels above $125 \mathrm{mg} /$ dl $(6.9 \mathrm{mmol} / \mathrm{L})$ or serum glucose concentration of more than or equal to $150 \mathrm{mg} / \mathrm{dl}(8.3 \mathrm{mmol} / \mathrm{L}){ }^{2}$ Intervention is recommended with neonates presenting two consecutive readings (at least two hours apart) of blood glucose levels above 252 $\mathrm{mg} / \mathrm{dl}(14 \mathrm{mmol} / \mathrm{L})$ or even a single reading of more than $216 \mathrm{mg} / \mathrm{dl}(12 \mathrm{mmol} / \mathrm{L})$ in the presence of glycosuria. ${ }^{3}$

The $1^{\text {st }}$ week of life, more specifically, $1^{\text {st }} 3$ to 5 days are highly vulnerable and neonates are highly prone to neonatal hyperglycemia in this period. ${ }^{4}$ Hyperglycemia is known to have an indirect linkage with birth weight and gestational age. ${ }^{5}$ Newborns weighing less than $1000 \mathrm{gm}$ are estimated to have $72 \%$ prevalence of hyperglycemia in comparison to less than $5 \%$ among newborns with birth weight of more than 2500 gm. ${ }^{6}$ Prematurity, intrauterine growth retardation (IUGR), stress, intravenous (IV) lipid infusion, birth asphyxia, high rates of infusion of glucose, nonexistence of enteral feeding and some drugs like theophylline, dopamine and steroids are some of the other known risk factors for hyperglycemia among neonates. ${ }^{7,8}$

Pathophysiology of hyperglycemia among neonates involves increased endogenous glucose production, hypo-insulinemia, insensitivity/ resistance of insulin receptors, catecholamine and some anti-insulin hormones. ${ }^{1}$ Hyperglycemia may present with or without symptoms. Common symptoms of hyperglycemia include dehydration, fever and inability to thrive. Many a times, hyperglycemia is the $1^{\text {st }}$ presentation indicating diabetes mellitus among neonates. ${ }^{9}$

Local data lacks about aspects of neonatal hyperglycemia while international researchers have shown variable relationship between hyperglycemia and commonly found morbidities 
among these neonates like intra-ventricular hemorrhage (IVH), infections, necrotizing enterocolitis (NEC), increased length of hospital stay. ${ }^{10,11}$ The current study was aimed to find out morbidity and mortality associated with hyperglycemia among neonates at our setting. The results of this study will help us designing tools and techniques to handle commonly associated aspects of hyperglycemia in neonates presenting at our institution.

\section{MATERIAL \& METHODS}

Department of Neonatology, Civil Hospital, Bahawalpur was the venue for this observational case-control study from $1^{\text {st }}$ July 2019 to $31^{\text {st }}$ December 2019. Approval from Institutional Ethical Committee was sought for this research. Informed consent was taken from parents/ guardians of all the study participants.

For cases having hyperglycemia the sample size was calculated according to the formula: $\mathrm{n}=\mathrm{z} 2$ * $p$ * $(1-p) / e 2$.

Where: $z=1.96$ for a confidence level (a) of 95\%, $p=50 \%$, e $=$ margin of error as $10 \%$.

Sample size for cases having hyperglycemia turned out to be 97 . Another 97 neonates who were euglycemic matched for age, weight, gestational age and clinical status served as controls. So, the study included 194 neonates (97 each for both groups). Hyperglycemia was labeled as glucose levels above $125 \mathrm{mg} / \mathrm{dl}$ (6.9 $\mathrm{mmol} / \mathrm{L})$ or serum glucose concentration of more than or equal to $150 \mathrm{mg} / \mathrm{dl}(8.3 \mathrm{mmol} / \mathrm{L})$. Neonates having any kind of congenital malformations or whose parents/guardians did not give permission for inclusion in this study were excluded from his study.

Data like age (days), gender and weight were noted for all while presence of morbidities like IVH, NEC or infections were also recorded. Outcome among study participants of both groups was noted in terms of length of hospital stay and discharged/expired.

All the study information was noted on a predesigned proforma. SPSS version 21.0 was used for data handling and analysis. Chi square test was used to note association of study variables with study groups and $p$ value less than or equal to 0.05 was taken as statistically significant.

\section{RESULTS}

Out of a total of 194 study participants, 114 $(58.8 \%)$ were male and 80 (41.2\%) female. Overall, majority of the neonates, 101 (52.1\%) had age between 1 to 7 days while 84 (43.3\%) had birth weight below 1.5 kilograms. There was no statistical difference between gender, age and birth weight between cases and controls ( $p$ value $>0.05)$.

In terms of morbidity, significantly more neonates had morbidity among cases as compared to controls ( $p$ value < 0.001). Among cases, 48 (49.5\%) had IVH in comparison to 23 (23.7\%) in controls ( $p$ value $<0.001$ ) representing OR of 3.152 (95\% Cl: 1.705-5.826). Among cases, NEC was seen in $72(74.2 \%)$ as compared to 20 (20.6\%) among controls ( $p$ value $<0.001$ ) representing OR of 11.088 (95\% Cl: 5.674-21.670). Regarding infections, 55 (56.7\%) neonates had infections in comparison to $24(24.7 \%)$ controls ( $p$ value < $0,001)$ representing OR of 3.983 (95\% Cl: 2.1617.342).

Significantly more cases, 57 (58.8\%) expired in comparison to 38 (39.2\%) controls (p value 0.006 ). Length of hospital stay was also significantly more prolonged among cases as compared to controls ( $p$ value $<0.001)$

\section{DISCUSSION}

Mechanisms like iatrogenic causes, insufficiency to suppress hepatic glucose production and insulin resistance/intolerance. ${ }^{1}$ Present was the $1^{\text {st }}$ of its kind at our institution to find out impact of hyperglycemia in terms of morbidity and mortality among neonates. In the present study, male predominance was noted among study participants. Around the world, it is a common finding that more male are brought to healthcare facilities to find medical care. 


\begin{tabular}{|l|c|c|c|}
\hline \multicolumn{2}{|c|}{ Characteristics } & Cases (n=97) & Controls (n-97) \\
\hline \multirow{3}{*}{ Gender } & Male & 58 & 56 \\
\hline & Female & 41 & 39 \\
\hline \multirow{3}{*}{ Age (days) } & $<1$ & $21(21.6 \%)$ & $17(17.5 \%)$ \\
\hline \multirow{3}{*}{ Birth Weight $(\mathrm{kg})$} & $1-7$ & $51(52.6 \%)$ & $50(51.5 \%)$ \\
\hline & $8-14$ & $11(11.3 \%)$ & $16((16.5 \%)$ \\
\hline & $15-21$ & $9(9.3 \%)$ & $8(8.2 \%)$ \\
\hline & $22-28$ & $5(5.2 \%)$ & $6(6.2 \%)$ \\
\hline & $<1.5$ & $43(44.3 \%)$ & $41(42.3 \%)$ \\
\hline
\end{tabular}

Table-I. Characteristics of Study Participants $(n=194)$.

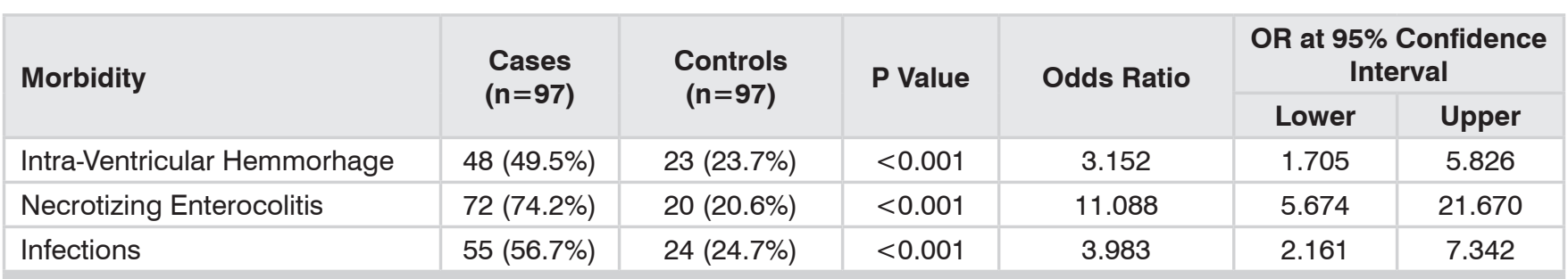

Table-II. Morbidity comparisons between cases and controls $(n=194)$.

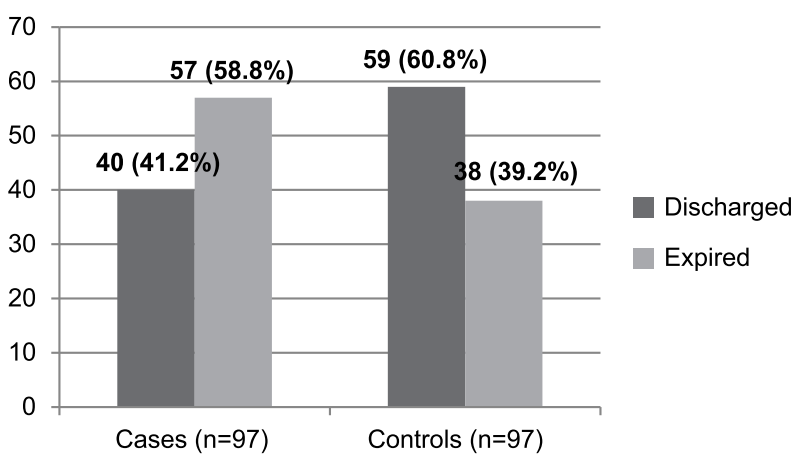

Figure-1. Outcome comparison between cases and controls.

Sabzehei $\mathrm{MK}^{6}$ et al and Alexandrou $\mathrm{G}$ et al ${ }^{9}$ also noted more males to have hyperglycemia in their researches. Likewise, a local study from Lahore ${ }^{12}$ noted male to female ratio of 1.8 times which is close to what we noted in the present study.

Rozance PJ and Hay WW $^{4}$ concluded that neonates with birth weight of less than or equal to $1 \mathrm{~kg}$ have 18 times more chance of having hyperglycemia in comparison to those who are between 1 to $2 \mathrm{~kg}$. In the present study, 44.3\% of the neonates with hyperglycemia had birth weight less than $1.5 \mathrm{~kg}$. Being low weight given enhancement to inheriting complex mechanisms like increased endogenous glucose production, hypoinsulinemia, insulin receptor insensitivity or resistance. ${ }^{13,14}$ Very similar to what we noted, Gul R et $\mathrm{al}^{12}$ found $48 \%$ of the cases having hyperglycemia to be having birth weight of less than or equal to $1.5 \mathrm{~kg}$. Yoo HS et al ${ }^{15}$ while observing extremely low birth weight newborns noted $85 \%$ of the cases to have hyperglycemia. Beardsall $\mathrm{K}$ et $\mathrm{al}^{16}$ also observed $80 \%$ of their very low birth weight cases to have hyperglycemia.

In the present study, $74.2 \%$ of the neonates were reported within $1^{\text {st }}$ week of life. Neonates are more prone to have hyperglycemia during $1^{\text {st }}$ of life because of stress aiding to alteration in glucose metabolism resulting in hyperglycemia. ${ }^{1,4}$ Many researchers from around the world have recorded that $60 \%$ to $85 \%$ of the neonates with hyperglycemia are reported within $1^{\text {st }}$ week of life ${ }^{2,5}$ which is exactly what we noted in the present study. Another local study from Lahore ${ }^{12}$ noted $74 \%$ of their neonates having hyperglycemia to be in $1^{\text {st }}$ week of life.

Presence of NEC among cases having hyperglycemia have been reported with varying results. We noted $74.2 \%$ of the neonates having 
hyperglycemia had NEC. Very similar to our findings, Gul R and Colleagues ${ }^{12}$ found $70.8 \%$ of their neonates having hyperglycemia to have NEC. Mohamed $S$ et al $^{17}$ noted prevalence of NEC to be $4.1 \%$ among neonates having hyperglycemia while Lugt NM et $\mathrm{al}^{18}$ and Sabzehei MK et $\mathrm{al}^{6}$ noted this to $2 \%$ and $33 \%$ respectively. The reason for this low prevalence in other studies could be because those researchers only included cases that met stage II and III of Modified Bell's criteria while we included stage 1 cases along with those as well. Our results were well in accordance to local findings where similar diagnostic criteria for NEC was employed. ${ }^{12}$

Hyperglycemia is known to impact white blood cells so this could be an important reason why increased chances of having infections lie with neonates having hyperglycemia. ${ }^{12}$ Bekhof $\mathrm{J}$ et al ${ }^{19}$ found infections to be present among $47.2 \%$ of their neonates having hyperglycemia which is well in accordance to our results where we noted $56.7 \%$ of our neonates having hyperglycemia to accompany infections. Other local researchers ${ }^{12}$ have noted $50 \%$ of their neonates to have infections which are very close to present findings. Contrary to our results, studies done from other parts of the world have seen infections to be present among 29-36.4\% of their neonates with hyperglycemia. ${ }^{6,16}$ The reason for those authors to find infections less commonly affecting neonates with hyperglycemia could be because they only labeled infections on the basis of blood culture reports while we used clinical and laboratory investigations for this purpose.

Hyperglycemia is thought to cause hyperosmolarity which could be the reason for brain cell dehydration, capillary dilatation as well as cerebral bleeding. ${ }^{12}$ In the present work, we noted almost half of our cases to have IVH which is very close to what has been found around the globe where IVH has been noted to be ranging between $36-45.8 \%$ of the neonates with hyperglycemia. ${ }^{11-16}$ USG cranial is a common way of diagnosing IVH among neonates ${ }^{12}$ and same method was applied in the present study.

Neonates having hyperglycemia are noted to have more chances of having complications following hyperglycemia that could prolong their length of hospital stay and adverse outcomes in comparison to other neonates. ${ }^{6}$ In the current study, we noted significantly more neonates to have expired. Very similar to our findings, a study done in Lahore ${ }^{12}$, found the neonates with hyperglycemia to have significantly prolonged length of hospital stay (OR 0.821, 95\% Cl:0.721-0.935, $p=0.028$ ), lower discharge rates (OR 0.739, 95\% Cl:0553-0.988, $\mathrm{p}=0.040$ ) and higher mortality (OR 1.353, 95\% Cl:1.012-1.809, $p=0.040)$.

\section{CONCLUSION}

Neonates having hyperglycemia not only are at significantly increased risk of having morbidities like IVH, NEC and infections but they also have high risk of mortality.

Copyright(C) 13 Apr, 2020.

\section{REFERENCES}

1. Simsek DG, Ecevit A, Hatipoglu N, Coban A, Arisoy AE, Bas $F$, et al. Neonatal hyperglycemia, which threshold value, diagnostic approach and treatment?: Turkish neonatal and pediatric endocrinology and diabetes societies consensus report. Turk Pediatri Ars. 2018; 53(Suppl 1): S234-S238.

2. Jain V, Chen M, Menon K. Disorders of carbohydrate metabolism. Gleason C A, Devaskar S U. Avery's Diseases of the Newborn. 9th Ed: USA; Saunders 2012; 1327-9.

3. Brewster B, Caldwell N, Rackham O. Hyperglycaemia in neonates: Clinical Guidelines. NHS Guidelines 2010.

4. Rozance PJ, Hay WW. Neonatal hyperglycemia. NeoReviews 2010; 11(11):e632-8.

5. Van der Lung NM, Smits-Wientjens V, Van Zwieten P, Walther F. Short and long term outcome of neonatal hyperglycemia in very preterm infants: A retrospective follow-up study. BMC Pediatr 2010; 10:52.

6. Sabzehei MK, Afjeh SA, Shakiba M, Alizadeh P, Shamshiri AR, Esmaili F. Hyperglycemia in VLBW Infants; Incidence, Risk Factors and Outcome. Arch Iran Med 2014; 17(6):429-34.

7. Uhing MR, Kliegman RM. Glucose, calcium and magnesium. In: Fanaroff A A, Fanaroff JM. Klaus \& Fanaroff's care of the high risk neonates. WB Saunders, Philadelphia 2013; 298-9. 
8. Obasa $\mathrm{T}$ O, Adesiyum $\mathrm{O} \mathrm{O}$, Mokuolu $\mathrm{O}$ A. Transient neonatal diabetes or neonatal hyperglycemia: a case report. Niger J Paed 2013; 40(2):192-4.

9. Alexandrou G, Skiold B, Karlen J, Tessma MK, Norman $M$, Aden $U$, et al. Early hyperglycemia is a risk factor for death and white matter reduction in preterm infants. Pediatrics 2010; 125:584-91.

10. Mittal A, Gupta R, Sharma S, Aggarwal KC. Stress induced hyperglycemia in a term baby mimicking diabetic ketoacidosis with stroke. J ClinNeonatol 2013; 2(4):190-2.

11. Heimann K, Peschgens T, Kwieeien R, Stanzel S, Hoernchen $\mathrm{H}$, Merz U. Are recurrent hyperglycemic episodes and median blood glucose level a prognostic factor for increased morbidity and mortality in premature infants $\leq 1500 \mathrm{gm}$. J Perinat Med 2007; 35: 245-8.

12. Gul R, Infan KA, Sheikh M, Javaid S, Haroon F, Fatima S. Is hyperglycemia a risk factor for neonatal morbidity and mortality? Pak Armed Forces Med J 2017; 67(4):621-6.

13. Alsweler JM, Harding JE, Bloomfield FH. Tight glycemic control with insulin in hyperglycemic preterm babies: A randomized control trial. Pediatrics 2012; 129(4):639-47.
14. Manzoni P, Castagnola E, Mostert M, Sala U, Galletto P, Gomirato $G$. Hyperglycaemia as a possible marker of invasive fungal infection in preterm neonates. Acta Paediatr 2006; 95(4):486-93.

15. Yoo HS, Ahn SY, Lee MS, Han YM, Sang SI, Chang YS et al. Permissive hyperglycemia in extremely low birth weight infants. J Korean Med Sci 2013; 28(3):450-60.

16. Beardsall K, Vanharsbrouck S, Ogilvy-Stuart AL, Vahole $\mathrm{C}$, Palmer R, van Weissenbrunch $\mathrm{M}$ et al. Prevalence and determinants of hyperglycemia in very low birth weight infants: Cohort analysis of nirture study. J Ped 2010; 157(5):715-9.

17. Mohamed S, Murray JM, Dagle JM, Colaizy T. Hyperglycemia as a risk factor for development of retinopathy of prematurity. BMC Pediatrics 2013; 13:78.

18. Lugt NM, Wintjens V EHJ, Zwieten PH, Walther FJ. Short and long term outcome of neonatal hyperglycemia in very preterm infants: A retrospective follow-up study. BMC Pediatrics 2010; 10:52.

19. Bekhof J, Kollen B J, Kok JH, Straaten H. Glycosuria as an early marker of late onset sepsis in preterm: A prospective cohort study. BMC Pediatrics 2015; 15:125.

\begin{tabular}{|c|c|c|c|}
\hline \multicolumn{2}{|c}{ AUTHORSHIP AND CONTRIBUTION DECLARATION } \\
\hline Sr. \# & \multicolumn{1}{|c|}{ Author(s) Full Name } & \multicolumn{1}{|c|}{ Contribution to the paper } & Author(s) Signature \\
\hline 1 & Muhammad Anwar & $\begin{array}{l}\text { Manuscript writing, Data } \\
\text { collection, Data entry, } \\
\text { Analysis and proof reading. } \\
\text { Data collection, data entry, } \\
\text { Review researh, Proof } \\
\text { reading, } \\
\text { Data collection, data entry, } \\
\text { Review research proof } \\
\text { reading. }\end{array}$ \\
\hline 3 & Ali Hammad & Muhammad Asghar Ali & \\
\hline
\end{tabular}

